\title{
Kinetic constraints on acylated homoserine lactone-based quorum sensing in marine environments
}

\author{
Laura Hmelo, Benjamin A. S. Van Mooy* \\ Department of Marine Chemistry and Geochemistry, Woods Hole Oceanographic Institution, Woods Hole, \\ Massachusetts 02543, USA
}

\begin{abstract}
Quorum sensing (QS) via acylated homoserine lactones (AHLs) was discovered in the ocean, yet AHLs are expected to be very short-lived at seawater $\mathrm{pH}$ due to rapid abiotic degradation. Quorum quenching, the enzymatic degradation of AHLs, is also likely. To better understand the potential for QS to regulate behaviors of marine bacteria, we investigated the degradation of a variety of AHL molecules in several types of seawater media. We did this by incubating AHLs and tracking their concentration using HPLC/electrospray-ionization mass-spectrometry (HPLC/ESI-MS). AHL concentrations decreased with time, and degradation rate coefficients were calculated by applying a first-order rate law. The rate of abiotic degradation showed strong dependence on acyl chain length and the presence of 3-oxo substitutions on the acyl chain. We found that the rate of abiotic degradation of AHLs in artificial seawater was much slower than that predicted by an oft-cited equation for non-marine media that takes only $\mathrm{pH}$ into account. However, AHLs degraded more rapidly in natural seawater than in artificial seawater, an observation we found to be due to quorum quenching enzyme activity. By applying calculated degradation rates in a simple steady-state calculation, we suggest that despite the observed quorum quenching activity, AHLs are likely to be viable signals in organic particles and in other microbial 'hotpsots' in marine environments.
\end{abstract}

KEY WORDS: Quorum sensing • Quorum quenching $\cdot$ Marine bacteria $\cdot$ Acylated homoserine lactone HPLC $\cdot$ Mass spectrometry $\cdot$ Degradation

\section{INTRODUCTION}

The first description of bacterial quorum sensing (QS) arose from studies of the marine luminescent bacterium Vibrio fischeri, which colonizes the light organs of eukaryotic hosts, most famously, the Hawaiian bobtail squid Euprymna scalopies (Coffey 1967, Nealson et al. 1970, Eberhard et al. 1981, Kaplan \& Greenberg 1985). V. fischeri's QS system was found to be regulated by acylated homoserine lactones (AHLs), and AHL-based QS has been subsequently identified in numerous isolates of marine Proteobacteria (e.g. Eberhard et al. 1981, Gram et al. 2002, Wagner-Dobler et al. 2005). Since Proteobacteria often dominate marine microbial communities (Giovannoni \& Rappe 2000), AHL-based QS has the potential to be widespread in the sea. For example, Miller et al. (2005) invoked QSinduced bacterial luminescence to explain a 'milky sea' event where a $15400 \mathrm{~km}^{2}$ patch of the Arabian Sea was observed by satellite to glow for several days. These authors speculated that the light was produced by a dramatic increase in the local concentration of the luminescent bacterium $V$. harveyi in response to resources supplied by a coincident algal bloom.

In addition to luminescence, AHLs have been shown to regulate a number of potentially ecologically relevant phenotypes; these include siderophore production, hydrolytic enzyme activity and biofilm formation (Miller \& Bassler 2001 and references therein). These behaviors could play an important role in the degradation of sinking organic matter in the ocean, and since AHL-producing bacteria were first isolated from 
marine snow by Gram et al. (2002), QS has been increasingly implicated as a potentially significant process in the marine carbon cycle (e.g. Buchan et al. 2005, Ziervogel \& Arnosti 2008).

AHLs are not only signals for bacterial communication, they can also mediate the settlement of eukaryotic larvae on bacterial biofilms (Joint et al. 2002, Tait et al. 2005). Larvae have been shown to use the presence or absence of AHLs to determine the suitability of a surface for permanent settlement (Joint et al. 2002, Tait et al. 2005). AHL production in biofilms thus plays a role in the ecology of higher organisms and in the biofouling of submerged surfaces such as ship hulls.

AHLs are active as QS signals only in their intact, lactone-based form, and the lactone moiety of AHLs is highly susceptible to rapid, base-catalyzed abiotic degradation (Yates et al. 2002, Tait et al. 2005). AHLs are very short-lived in aqueous media with $\mathrm{pH}$ in the range of seawater (Yates et al. 2002). Furthermore, it appears that AHLs are also degraded enzymatically in natural systems (Delalande et al. 2005, Wang \& Leadbetter 2005), a process that has been termed quorum quenching.

Taxonomic and functional specificity of AHLs is conferred by the length, degree of unsaturation, and presence or absence of oxo- and hydroxyl-substitution on the acyl chain. Multiple AHLs may be used by the same organism to regulate independent processes (Gonzalez \& Marketon 2003 and references therein). Importantly, the rate of abiotic degradation and quorum quenching also appears to be affected by these aforementioned variations in AHL structure (Yates et al. 2002, Delalande et al. 2005, Wang \& Leadbetter 2005). It is likely, although not demonstrated, that organisms will produce a particular suite of AHLs based on each molecule's stability in a given environment.

In the present study, we sought to quantify the rates of abiotic and enzymatic AHL degradation in seawater and to gain a better understanding of the conditions that must be met in order for AHL-based QS to take place in marine environments. We used HPLC/electrospray-ionization mass-spectrometry (HPLC/ESI-MS) to track the degradation of intact, biologically active AHLs in a number of seawater incubation experiments. Even though QS research owes its provenance to the study of marine bacteria, there have been few previous investigations of the stability of AHLs under natural seawater conditions (but see Tait et al. 2005).

\section{MATERIALS AND METHODS}

Nomenclature. We abbreviate the names of specific AHLs as (3O)C $(n)$-HSL, where $n$ refers to length of acyl side chain bound to homoserine lactone (HSL), and $3 \mathrm{O}$ indicates the presence of a 3-oxo (ketone) group on the acyl side chain (Fig. 1).

Incubation design. Rates of AHL degradation were determined by incubating synthetic AHLs in defined liquid media and tracking their concentrations by HPLC/ESI-MS. Synthetic C4-, 3OC6-, C6-, C7-, 3OC8-, C8- and C12-HSL were purchased from Sigma-Aldrich and individual solutions were made with HPLC-grade methanol to a concentration of $500 \mu \mathrm{mol} \mathrm{l}^{-1}$. A $30 \mu \mathrm{l}$ aliquot of a standard was added to the bottom of a pre-combusted $40 \mathrm{ml}$ clear glass vial, and the methanol was allowed to evaporate from the bottom of the vial. Next, $30 \mathrm{ml}$ of liquid incubation media (defined below) was added. The vials were then sealed with UV-sterilized teflon-lined caps and incubated on the lab bench. All incubations were conducted at room temperature (approximately $23^{\circ} \mathrm{C}$ ). The final AHL concentration at the start of all experiments was $500 \mathrm{nmol} \mathrm{l}^{-1}$; this value is comparable to the range of AHL concentrations observed in culture media and measured in the light organs of Euprymna scolopes and E. morsei (0.4 to $400 \mathrm{nmol} \mathrm{l}^{-1}$ ) (Kaplan \& Greenberg 1985, Schaefer et al. 2002, Burton et al. 2005). All incubations were conducted such that triplicate incubations could be sacrificed at each time point for AHL extraction, analysis, and quantification.

Extraction and analysis of AHLs. Incubations were extracted 3 times with $13 \mathrm{ml}$ dichloromethane (Fisher Scientific). Immediately prior to extraction, $10 \mu \mathrm{l}$ of $500 \mathrm{mmol} \mathrm{l}^{-1}$ Z-homoserine lactone (Sigma-Aldrich) was added to the aqueous phase as an internal standard. The combined extracts were passed through a column of combusted sodium sulfate to remove residual water and then dried under nitrogen. Extracts were transferred in methanol to small glass vials for analysis on a Thermo Finnegan Surveyor HPLC coupled to a Thermo-Finnegan LCQ Deca-XP Mass Spectrometer through an electrospray-ionization interface. Separation of AHLs was achieved by running a watermethanol gradient through an Altima HP C18 reversephase chromatography column $(5 \mu \mathrm{m}, 2.1 \times 150 \mathrm{~mm}$; Agilent) with guard column. Solvent A was Milli-Q water $(0.1 \%$ formic acid) and solvent B was methanol ( $0.1 \%$ formic acid). The gradient program was as follows: 0 to $25 \mathrm{~min}$, gradient from $90 \% \mathrm{~A} / 10 \%$ B to $100 \%$ $\mathrm{B}_{\text {; }} 25$ to $26 \mathrm{~min}, 100 \% \mathrm{~B} ; 26$ to $27 \mathrm{~min}$, gradient to $90 \%$ $\mathrm{A} / 10 \% \mathrm{~B} ; 27$ to $36 \min 90 \% \mathrm{~A} / 10 \% \mathrm{~B}$ (column equilibration). Intact AHLs have masses, fragmentation patterns, and chromatographic properties that are distinct from their degradation products (data not shown), and the peak areas of the molecular ions from intact AHLs (Fig. 1) were integrated and converted to concentration units based on the recovery of the internal standard and comparison to standard curves. Standard curves were prepared daily with a fresh mixture of 


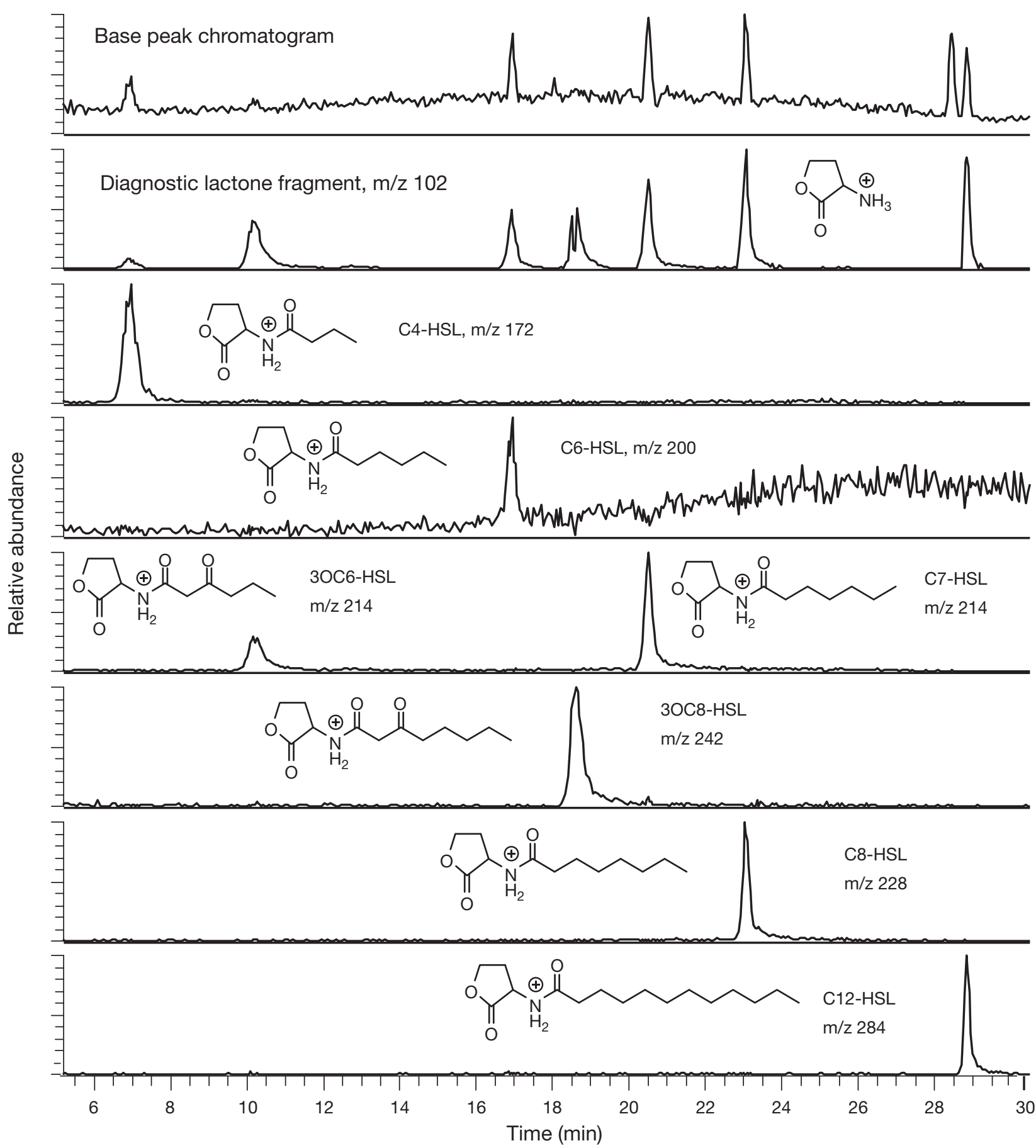

Fig. 1. Extracted ion chromatograms from HPLC/ESI-MS analysis of acylated homoserine lactones (AHLs). Molecular structures of C4-, 3OC6-, C6-, C7-, 3OC8-, C8-, and C12-HSL are inset next to the respective chromatogram. Names of specific AHLs are abbreviated as $(3 \mathrm{O}) \mathrm{C}(n)-\mathrm{HSL}$, where $n$ refers to the length of the acyl side chain bound to homoserine lactone (HSL) and $3 \mathrm{O}$ indicates the presence of a 3-oxo (ketone) substituent on the acyl-side chain

AHLs, and the standard mixture was reanalyzed after every 6th sample.

Incubation media. All liquid incubation media were prepared immediately prior to their use in the AHL degradation incubations. Whole seawater for all incu- bation experiments was collected in March 2008 from Vineyard Sound, Massachusetts, USA $\left(41^{\circ} 32^{\prime} \mathrm{N}\right.$, $\left.70^{\circ} 40^{\prime} \mathrm{W}\right)$, and was filtered in the field through a coarse $(100 \mu \mathrm{m})$ mesh filter to remove seaweed and large particulates. Shortly thereafter in the laboratory, 
the seawater was filtered through a $0.22 \mu \mathrm{m}$ cellulose acetate bottle-top filter (Corning) under 200 mbar vacuum and the $\mathrm{pH}$ determined.

Artificial seawater was prepared using $18 \mathrm{M} \Omega$ Milli$\mathrm{Q}$ water according to the Trace MBL artificial seawater recipe: $423 \mathrm{mmol} \mathrm{l^{-1 }} \mathrm{NaCl} 8.27 \mathrm{mmol} \mathrm{l^{-1 }} \mathrm{KCl}$, $9.27 \mathrm{mmol} \mathrm{l}^{-1} \mathrm{CaCl}_{2}, 22.94 \mathrm{mmol} \mathrm{l}^{-1} \mathrm{MgCl}_{2}, 25.50 \mathrm{mmol}$ $\mathrm{l}^{-1} \mathrm{MgSO}_{4}, 2.14 \mathrm{mmol} \mathrm{l}^{-1} \mathrm{NaHCO}_{3}, 0.23 \mathrm{mmol} \mathrm{l}^{-1} \mathrm{SrCl}_{2}$. $0.07 \mathrm{mmol} \mathrm{l}^{-1} \mathrm{NaF}, 0.39 \mathrm{mmol} \mathrm{l}^{-1} \mathrm{H}_{3} \mathrm{BO}_{3}, 0.75 \mathrm{mmol} \mathrm{l}^{-1}$ $\mathrm{KBr}$. The artificial seawater was filtered through a $0.22 \mu \mathrm{m}$ cellulose acetate bottle-top filter (Corning) under 200 mbar vacuum, and the $\mathrm{pH}$ adjusted to that of Vineyard Sound seawater prior to being used in the degradation experiments by adding small quantities of $1 \mathrm{~mol} \mathrm{l}^{-1} \mathrm{HCl}$ and $1 \mathrm{~mol} \mathrm{l}^{-1} \mathrm{NaOH}$ as required.

To assess the impact of enzymes on the degradation of AHLs in Vineyard Sound seawater, endogenous enzymes were denatured either by treating the seawater with $40 \mu \mathrm{g} \mathrm{l}^{-1}$ Proteinase-K (Fisher) and incubating at $37^{\circ} \mathrm{C}$ for $1 \mathrm{~h}$, or by boiling the seawater for $10 \mathrm{~min}$. The $\mathrm{pH}$ of these treated seawater media was also measured and adjusted to $\mathrm{pH} 7.9$.

Data analysis. The decrease in the concentrations of these molecules with time was modeled using the firstorder rate law equation:

$$
\ln \frac{C}{C_{0}}=-k t
$$

where $C$ is the concentration at a given time point, $C_{0}$ is the concentration at time zero, $t$ is the length of the incubation (h), and $k$ is the degradation rate coefficient $\left(\mathrm{h}^{-1}\right)$. Data when plotted in this manner will fall in a straight line if the reaction kinetics are first order; $k$ is the negative slope of the line and is reported $\pm \mathrm{SE}$ of the slope. We estimate that 2 slopes from 2 sets of degradation experiments are different from one another when their difference is greater than twice the combined SE of the 2 slopes.

Incubations with C6-HSL and 3OC6-HSL were conducted such that they could be sampled at 5 time points. First-order kinetics were established for both C6-HSL (see Fig. 2) and 3OC6-HSL. Subsequently, only 2 time points were measured and used to determine degradation rate coefficients of the other AHLs.

\section{RESULTS}

The AHLs C6- and 3OC6-HSL are the archetypal AHLs from vibrios and are common to many other QS Proteobacteria (Miller \& Bassler 2001); the present study focused primarily on these 2 molecules. In our incubation experiments, all of which were conducted at $\mathrm{pH} 7.9$ (the $\mathrm{pH}$ of Vineyard Sound seawater), we found that the concentrations of these AHLs decreased with time according to first-order degradation kinetics in natural and artificial media (Fig. 2). Loss of AHLs by first-order kinetics was observed whether the AHL was incubated under abiotic conditions (artificial seawater) or in natural seawater from Vineyard Sound (filtered through $0.2 \mu \mathrm{m}$ pore-size membrane).

We observed that C6-, 3OC6-, and 3OC8-HSL degraded more rapidly in natural seawater than in artificial seawater (Fig. 3). The degradation rate coefficients observed in natural seawater were $0.043 \pm$ $0.003,0.116 \pm 0.005$, and $0.148 \pm 0.002 \mathrm{~h}^{-1}$ for $\mathrm{C} 6-$, 3OC6-, and 3OC8-HSL, respectively; whereas the degradation rate coefficients in artificial seawater were $0.028 \pm 0.001,0.094 \pm 0.002$, and $0.094 \pm$ $0.001 \mathrm{~h}^{-1}$, respectively. Regardless of media, the oxosubstituted AHLs (3OC6- and 3OC8-HSL) degraded at least twice as fast as C6-HSL.

We pretreated natural seawater with Proteinase-K to digest endogenous enzymatic proteins and found that this slowed the degradation of C6-, 3OC6-, and 3OC8HSL relative to that in untreated natural seawater (Fig. 3). The degradation rate coefficients in Proteinase-K treated natural seawater were $0.032 \pm 0.001$, $0.102 \pm 0.003$, and $0.102 \pm 0.004 \mathrm{~h}^{-1}$ for C6-, 3OC6-, and 3OC8-HSL, respectively, and were indistinguishable from the rates observed in artificial seawater. We performed a similar experiment by heat treating the natural seawater and the degradation rate coefficients also decreased, to $0.034 \pm 0.002,0.089 \pm 0.2$, and 0.087 $\pm 0.01 \mathrm{~h}^{-1}$, respectively.

The degradation rate coefficients of $\mathrm{C}_{4-}, \mathrm{C} 7-, \mathrm{C} 8-$, and $\mathrm{C} 12-\mathrm{HSLs}$ were also measured in natural and artificial seawater. We observed a chain-length dependence amongst straight-chain AHLs such that longerchain AHLs degraded more slowly than shorter-chain

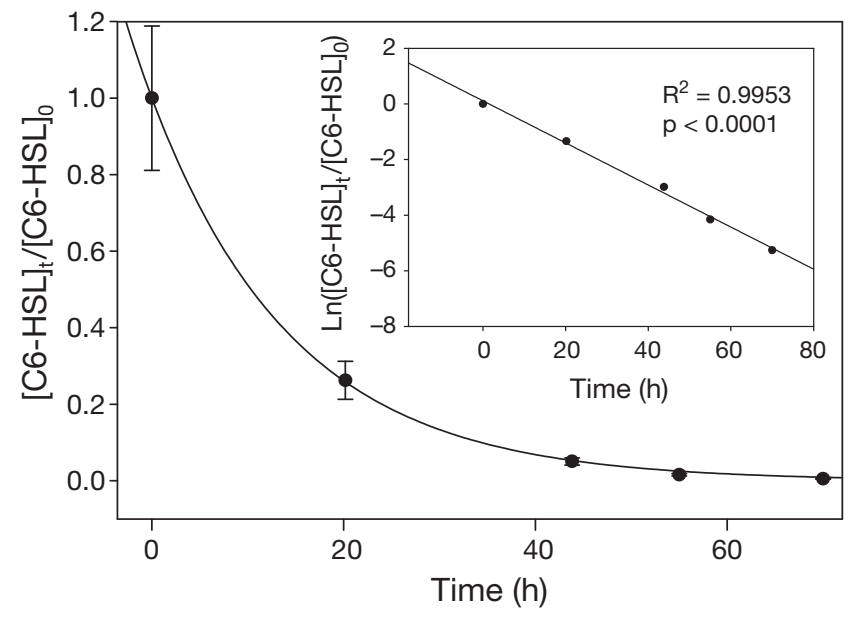

Fig. 2. Acylated homoserine lactone C6-HSL concentration over time during incubation in seawater from Vineyard Sound, Massachusetts, USA. Inset: natural log-transformed data as applied in Eq. (1) 

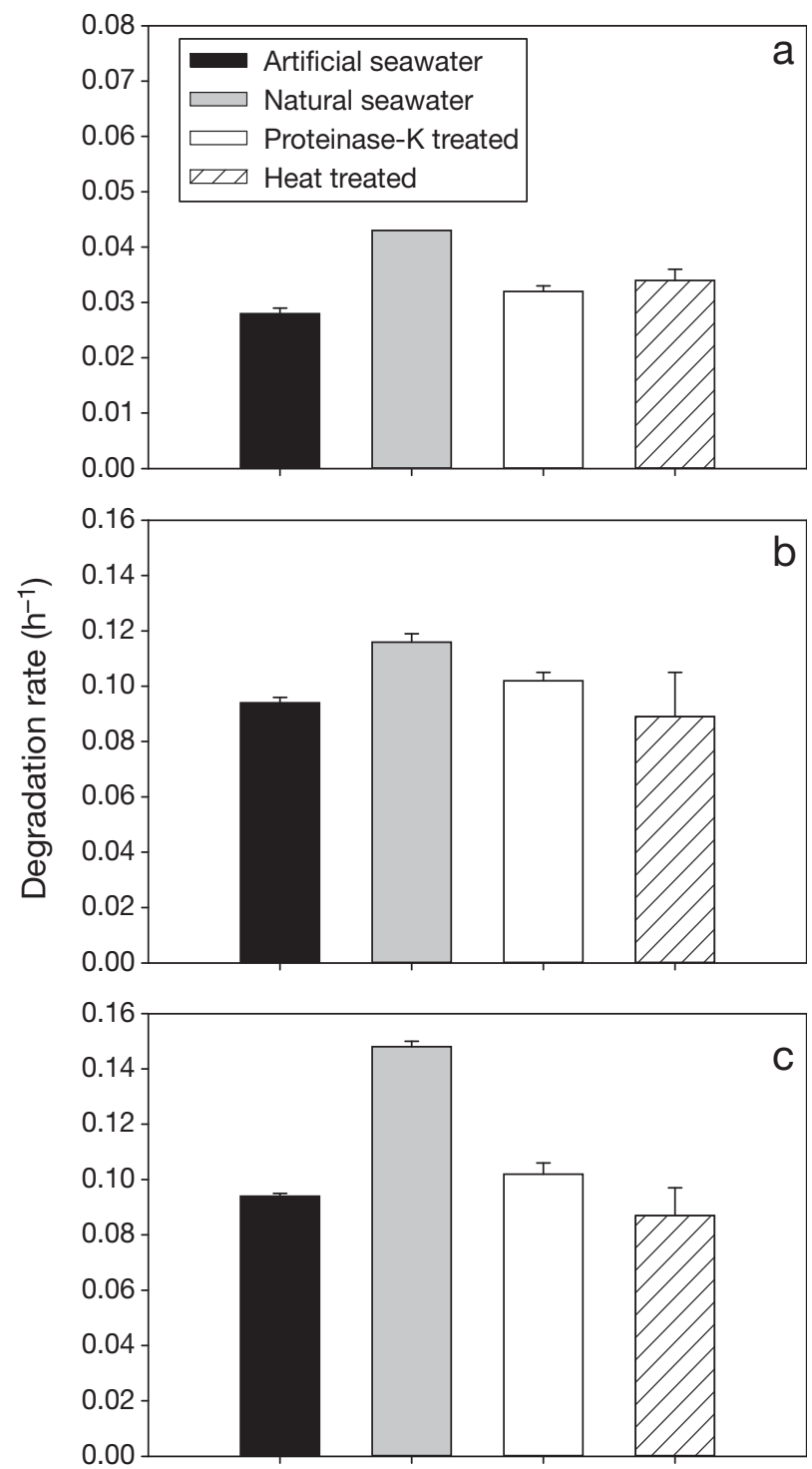

Fig. 3. Degradation rate coefficients $( \pm \mathrm{SE}$ ) of AHLs (a) C6HSL, (b) 3OC6-HSL and (c) 3OC8-HSL in artificial seawater, natural seawater, Proteinase-K treated natural seawater, and heat-treated natural seawater

AHLs (Fig. 4). This relationship did not appear to hold for 3-oxo substituted AHLs, although only 2 molecules of this type were examined.

We assessed the potential impact of abiotic sorption of AHLs to the glass walls of the incubation vials; this was done in incubations of C6-HSL and 3OC6-HSL conducted with different volumes of water but in the same $40 \mathrm{ml}$ vials. By doing this, we affected a 5 -fold difference in the surface area to volume ratio of the incubations, but observed no measurable differences in degradation rate coefficients. Thus, surface sorption did not affect the observed rates of AHL degradation and will not be further discussed.

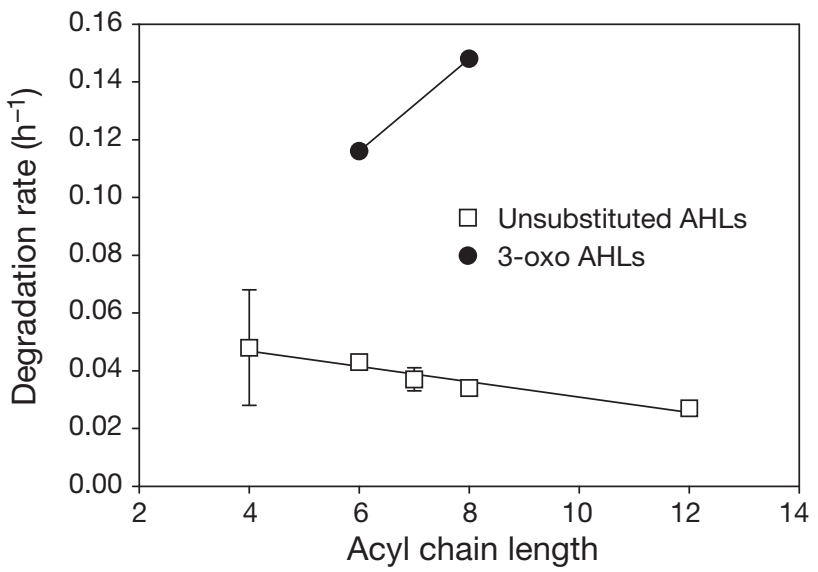

Fig. 4. Degradation rate coefficients $( \pm \mathrm{SE})$ of various AHLs in natural seawater versus the length of the acyl side chain. Linear regression for unsubstituted AHLs: $k=-0.059(n)+$ $1.328\left(\mathrm{R}^{2}=0.935, \mathrm{p}<0.001\right)$

\section{DISCUSSION}

The effect of $\mathrm{pH}$ on the abiotic degradation of AHLs in aqueous media (Luria-Bertani media, organic buffers, or pure water) is well established: AHLs degrade more rapidly at higher $\mathrm{pH}$ (Yates et al. 2002, Delalande et al. 2005). In seawater, with an average $\mathrm{pH}$ of 8.2, AHLs are expected to degrade quite rapidly. However, to our knowledge, the degradation rates of AHLs in seawater have yet to be explicitly determined. In the present study, we focused our attention on understanding the effects of both abiotic degradation and quorum quenching enzyme activity on AHL degradation in natural seawater collected from Vineyard Sound.

In artificial seawater, only abiotic factors influenced the degradation of AHLs. Both unsubstituted and 3oxo-substituted AHLs are highly susceptible to degradation by base-catalyzed abiotic lactonolysis (Yates et al. 2002). In addition, 3-oxo substituted AHLs may degrade via an abiotic Claisen-like rearrangement (Kaufmann et al. 2005). Accordingly, 3OC6-HSL degraded significantly faster than C6HSL in artificial seawater and all natural seawaterbased media we tested (Fig. 3). However, we observed that 3OC6-HSL degraded much more slowly in artificial seawater $\left(0.094 \pm 0.002 \mathrm{~h}^{-1}\right)$ than the rate predicted for non-marine media by the $\mathrm{pH}$ dependent formula $\left(0.26 \mathrm{~h}^{-1}\right)$ of Schaefer et al. (2000) which is often cited (e.g. Wang \& Leadbetter 2005). Furthermore, we found that abiotic degradation of unsubstituted AHLs proceeded at rates slower than those recently reported by Decho et al. (2009) at pH 8.2, which were also apparently determined in nonmarine media. This suggests that abiotic AHL degra- 
dation occurs more slowly in seawater relative to other aqueous media.

In contrast to artificial seawater, AHLs in natural seawater were subject to the above abiotic degradation mechanisms as well as attack from quorum quenching enzymes. In natural seawater, the degradation rate coefficients for C6-, 3OC6-, and 3OC8-HSL were 54, 23, and $57 \%$, respectively, faster than in artificial seawater; we assert that this difference was due to quorum quenching activity. Evidence for this assertion comes from the observation that the denaturation of endogenous proteins in natural seawater decreased the rates of AHL degradation such that they were indistinguishable from artificial seawater, which confirms that at least a significant fraction of the observed quorum quenching activity was due to free enzymatic proteins.

Our observations of quorum quenching activity in seawater are striking since they suggest that the marine microbiota in Vineyard Sound have invested in enzymes to accelerate the degradation of AHL molecules that are already relatively short-lived in seawater due to abiotic degradation processes. Alternatively, the AHLs may have been degraded by non-specific enzyme activity, which suggests that quorum quenching is not the result of a specific strategy directed at disrupting QS systems, but is merely the fortuitous result of entirely unrelated enzyme activity. Regardless, our observation of active quorum quenching in natural seawater outside of biofilms suggests that this process could place important constraints on the role of AHLs in eukaryotic larval recruitment under natural conditions.

In the present study, short-chain AHLs degraded more rapidly than long-chain AHLs in both artificial seawater and filtered natural seawater. This result is consistent with previous studies in freshwater media showing that AHLs with shorter acyl chains are shorter-lived (Yates et al. 2002). Longer-chain AHLs may be better optimized to function in a seawater medium due to their longer half-life with respect to abiotic degradation. This inference is consistent with numerous reports that AHL-producing marine bacterial isolates often produce long-chain AHLs rather than short-chain AHLs (Schaefer et al. 2002, WagnerDobler et al. 2005). On the other hand, bacteria in marine environments could use AHLs with shorter acyl chains to communicate over relatively shorter distances. However, organisms using shorter-chain AHLs would be required to synthesize them at a greater rate to achieve a given concentration in the environment.

Using our measured rate coefficient for 3OC6-HSL degradation in natural Vineyard Sound seawater as an example, we can make a steady-state estimate of the rate of AHL production required to maintain 3OC6HSL at concentrations sufficient for the induction of bacterial QS systems in marine environments. We attempted to measure AHLs directly in natural seawater from Vineyard Sound, but found that levels were below our analytical limit of detection of approximately $10 \mathrm{pmol} \mathrm{l}^{-1}$. QS systems in Proteobacteria are generally not induced until AHL concentrations reach at least $10 \mathrm{nmol} \mathrm{l}^{-1}$ (Kaplan \& Greenberg 1985), which is 3 orders of magnitude higher than our detection limit; this suggests that AHL-regulated behaviors are very unlikely to be active in open seawater. However, if we assume the required concentration of 3OC6-HSL in seawater is indeed $10 \mathrm{nmol}^{-1}$, then we can calculate the maximum first-order molar degradation rate of this AHL as simply the product of this concentration and the measured degradation rate coefficient $(k)$ :

$$
\begin{gathered}
\text { Degradation rate }=k[3 \mathrm{OC} 6-\mathrm{HSL}]=0.12 \mathrm{~h}^{-1} \times \\
10 \mathrm{nmol} \mathrm{l}^{-1} \approx 1.2 \mathrm{nmol} \mathrm{l}^{-1} \mathrm{~h}^{-1}
\end{gathered}
$$

At steady-state, the degradation rate of this AHL would be equal to its production rate.

By using the 3OC6-HSL production rate, the required density of AHL-producing bacterial cells can also be estimated. Fully induced QS Proteobacteria synthesize AHLs at rates on the order of 1 amol cell ${ }^{-1} \mathrm{~h}^{-1}$ (Wang \& Leadbetter 2005), and so at steady-state, a minimum of $1.2 \times 10^{9}$ cells $^{-1}$ would be required in order for production to match our calculated molar degradation rate. While total cell concentrations in the open ocean may reach these concentrations, for monospecific concentrations to approach this level would require truly exceptional environmental conditions. Obviously, the uncertainty in this estimate could be as high as an order of magnitude. Nonetheless, this analysis suggests, as expected (Nealson et al. 1970), that QS thresholds are much more likely to occur in marine biofilms, such as those that occur on sinking particles where total bacterial cell concentrations in excess of $10^{11}$ cells $\mathrm{l}^{-1}$ are possible. These and other microbial 'hotspots' play a significant role in the marine carbon cycle (Azam \& Long 2001 and references therein).

The rates of AHL degradation determined in the present study enabled us to estimate the concentration of bacteria required to induce QS behaviors in natural marine systems. Our data do not preclude a bacterial origin for the large-scale 'milky sea' reported by Miller et al. (2005), but they do put constraints on the planktonic (i.e. non-biofilm) population densities that would be required for QS-induced proteobacterial luminescence events to occur in the open ocean.

Acknowledgements. We gratefully acknowledge H. Fredricks for assistance with HPLC/ESI-MS analyses. We also thank E. DeLong and C. Reddy for helpful conversations. This work was funded by a grant from the Office of Naval Research to B.A.S.V.M. (N0014-06-1-0134), and an NSF Graduate Student Fellowship to L.H. 


\section{LITERATURE CITED}

Azam F, Long RA (2001) Sea snow microcosms. Nature 414: 495-498

Buchan A, González JM, Heidelberg JF, Whitman WB and others (2005) Genome sequence of Silicibacter pomeroyi reveals adaptations to the marine environment. Nature 432:910-913

Burton EO, Read HW, Pellitteri MC, Hickey WJ (2005) Identification of acyl-homoserine lactone signal molecules produced by Nitrosomonas europaea strain Schmidt. Appl Environ Microbiol 71:4906-4909

Coffey JJ (1967) Inducible synthesis of bacterial luciferase: specificity and kinetics of induction. J Bacteriol 94: 1638-1647

Decho AW, Visscher PT, Ferry J, Kawaguchi T and others (2009) Autoinducers extracted from microbial mats reveal a surprising diversity of $\mathrm{N}$-acylhomoserine lactones (AHLs) and abundance changes that may relate to diel $\mathrm{pH}$. Environ Microbiol 11:409-420

Delalande L, Faure D, Raffoux A, Uroz S and others (2005) Nhexanoyl-L-homoserine lactone, a mediator of bacterial quorum-sensing regulation, exhibits plant-dependent stability and may be inactivated by germinating Lotus corniculatus seedlings. FEMS Microbiol Ecol 52:13-20

Eberhard A, Burlingame A, Eberhard C, Kenyon G, Nealson K, Oppenheimer N (1981) Structural identification of autoinducer of Photobacterium fischeri luciferase. Biochemistry 20:2444-2449

Giovannoni SJ, Rappe MS (2000) Evolution, diversity, and molecular ecology of marine prokaryotes. In: Kirchman DL (ed) Microbial ecology of the oceans. Wiley-Liss, New York, p 47-84

Gonzalez JE, Marketon MM (2003) Quorum sensing in nitrogen-fixing rhizobia. Microbiol Mol Biol Rev 67: 574-592

- Gram L, Grossart HP, Schlingloff A, Kiørboe T (2002) Possible quorum sensing in marine snow bacteria: production of acylated homoserine lactones by Roseobacter strains isolated from marine snow. Appl Environ Microbiol 68: 4111-4116

Joint I, Tait K, Callow ME, Callow JA, Milton D, Williams P, Camara M (2002) Cell-to-cell communication across the prokaryote-eukaryote boundary. Science 298:1207

Kaplan HB, Greenberg EP (1985) Diffusion of autoinducer is

Editorial responsibility: Craig Carlson,

Santa Barbara, California, USA involved in regulation of the Vibrio fischeri luminescence system. J Bacteriol 163:1210-1214

Kaufmann GF, Sartorio R, Lee SH, Rogers CJ and others (2005) Revisiting quorum sensing: discovery of additional chemical and biological functions for 3-oxo-N-acylhomoserine lactones. Proc Natl Acad Sci USA 102: 309-314

- Miller MB, Bassler BL (2001) Quorum sensing in bacteria. Annu Rev Microbiol 55:165-199

Miller SD, Haddock SHD, Elvidge CD, Lee TF (2005) Detection of a bioluminescent milky sea from space. Proc Natl Acad Sci USA 102:14181-14184

> Nealson KH, Platt T, Hastings JW (1970) Cellular control of the synthesis and activity of the bacterial luminescent system. J Bacteriol 104:313-322

Schaefer AL, Hanzelka BL, Parsek MR, Greenberg EP (2000) Detection, purification, and structural elucidation of the acylhomoserine lactone inducer of Vibrio fischeri luminescence and other related molecules. In: Abelson JN, Simon MI, Ziegler MM, Baldwin TO (eds) Methods in enzymology, Vol 305: Bioluminescence and chemiluminescence, Part C. Academic Press, San Diego, CA, p 288-301

Schaefer AL, Taylor TA, Beatty JT, Greenberg EP (2002) Long-chain acyl-homoserine lactone quorum-sensing regulation of Rhodobacter capsulatus gene transfer agent production. J Bacteriol 184:6515-6521

Tait K, Joint I, Daykin M, Milton DL, Williams P, Camara M (2005) Disruption of quorum sensing in seawater abolishes attraction of zoospores of the green alga Ulva to bacterial biofilms. Environ Microbiol 7:229-240

Wagner-Dobler I, Thiel V, Eberl L, Allgaier M and others (2005) Discovery of complex mixtures of novel long-chain quorum sensing signals in free-living and host-associated marine Alphaproteobacteria. ChemBioChem 6:2195-2206

Wang YJ, Leadbetter JR (2005) Rapid acyl-homoserine lactone quorum signal biodegradation in diverse soils. Appl Environ Microbiol 71:1291-1299

Yates EA, Philipp B, Buckley C, Atkinson S and others (2002) $\mathrm{N}$-acylhomoserine lactones undergo lactonolysis in a $\mathrm{pH}-$, temperature-, and acyl chain length-dependent manner during growth of Yersinia pseudotuberculosis and Pseudomonas aeruginosa. Infect Immun 70:5635-5646

Ziervogel K, Arnosti C (2008) Polysaccharide hydrolysis in aggregates and free enzyme activity in aggregate-free seawater from the northeastern Gulf of Mexico. Environ Microbiol 10:289-299

Submitted: July 21, 2008; Accepted: October 16, 2008

Proofs received from author(s): January 22, 2009 